\title{
Coping with spinal cord injury: personal and marital adjustment in the Hong Kong Chinese setting
}

\author{
RCK Chan*,1, PWH Lee ${ }^{2}$ and F Lieh-Mak ${ }^{2}$ \\ ${ }^{I}$ The Department of Psychology, The University of Hong Kong; ${ }^{2}$ The Department of Psychiatry, The University of \\ Hong Kong
}

Study design: A cross-sectional retrospective study was carried out with structured questionnaires and semi-structured interviews on 66 persons with spinal cord injury (SCI) and 40 spouses.

Objectives: The study aimed to explore the psychosocial adjustment of Hong Kong Chinese couples at the post SCI stage. An important study interest was the impact of care-giving in spouses of persons with SCI.

Setting: Three major regional rehabilitation centres and one community resource centre in Hong Kong.

Methods: A set of psychometric measures tapping different aspects of psychological functioning was included. These were locus of control (Levenson's Internality, Powerful Others, and Chance Scale), perceived social support (Provision of Social Relationship), coping strategies (Ways of Coping Checklist), marital adjustment (Dyadic Adjustment Scale), caregiving burden (Caregiver Burden Inventory), depression (Beck Depression Inventory), life satisfaction (Satisfaction with Life Situation), and social role adjustment (Katz Adjustment Scale - Relative Form).

Results: Persons with SCI with pre-injury marriage were more depressed $(P<0.05)$ as compared with those with post-injury marriage. However, the two groups did not differ in terms of satisfaction with life situation and social role dissatisfaction. The spouses in the preinjury marriage reported a significantly higher score in time-dependent burden than those in the post-injury marriage $(P<0.05)$. Care-giving burden was associated with locus of control, social support, and modes of coping $(P<0.05)$.

Conclusion: The impact of SCI is a long-lasting effect not limited to the patients but also extending to their spouses. Findings from the adjustment outcomes and coping styles of persons with SCI and their spouses indicate that they are not passive victims. A similar injury may produce different outcomes in different individuals. Rehabilitation professionals should thus be alert to both the couple's differing needs and idiosyncrasies in their helping process. Spinal Cord (2000) 38, 687-696

Keywords: personal and marital adjustment; persons with SCI; spouses; Hong Kong Chinese

\section{Introduction}

The abrupt onset of spinal cord injury (SCI) is tragic and has a profound impact on the individuals and their significant others. With increased survival rate and life-span, ${ }^{1}$ persons with SCI may have to live with their disability for a much longer period of time till the natural end of their lives. The potential impact of the SCI include the aggravation of old and new problems as well as the creation of a significant burden on spouses and family members. Adjustment

*Correspondence: RCK Chan, Department of Psychology, The University of Hong Kong, Pokfulam Road, Hong Kong, China to SCI had previously been explored in terms of stage of coping, ${ }^{2,3}$ personality-trait perspective, ${ }^{4,5}$ and socio-psychological perspective. ${ }^{6,7}$ Although stage theorists provide a theoretical framework for description of the adjustment process, the hypothesized stages have yet to be fully validated. ${ }^{8,9}$ On the other hand, it is generally agreed that there is no unitary personality style associated with any disability. 810 Several other variables, however, had been noted as being associated with a better adjustment to SCI. These are young age, ${ }^{112}$ financial security, ${ }_{12-14}$ persons with more internal locus of control, ${ }^{15-18}$ and good social support. ${ }^{8,19-21}$ The socio-psychological perspective alerts us to adopt a broader 
interpretation of adjustment and emphasizes that interpersonal support and re-socialization are important signposts in the total adjustment process with SCI. The spouse as the most intimate companion of the person with SCI may also experience many similar stresses related to the injury in terms of financial constraints, psychological distress, disturbed family, marital and social relationships. However, the extent of disruption of family life and marital relationship resulting from the injury has not yet been fully studied from the family members' perspective. ${ }^{22-24}$

Good marital relationship is regarded as an important factor affecting the psychosocial outcomes of persons with SCI and their spouses. ${ }^{25-27}$ SCI married couples tended to have more relationship problems when the disabled partner's level of functional independence is low. ${ }^{23,28}$ Persons with SCI in distressed marriages tend to engage in relatively fewer activities alone and are less willing or able to self-initiate social activity. Persons with SCI in unsatisfactory marriages tended also to spend a considerable amount of time in solitary and disengaged behaviour. ${ }^{29}$ Crewe and her associates ${ }^{30-32}$ found that those who were married after the injury tended to be more satisfied with their living arrangements, social lives, general health, emotional adjustment, and sense of control over their lives than those married before the injury. The persons with SCI who were married after the injury were also more likely to be working and socially active outside their homes. These authors suggested that for marriages prior to SCI, disability may be something neither of the couple bargains for as part of the marriage agreement in those marriages before the injury, and it often seemed to cause resentment or resignation. The couple also has to adjust to a reversal of roles or has to learn new ways of communicating feelings and needs.

In studying care-giving burden of spouses of persons with SCI, Schulz and co-workers ${ }^{27}$ noted that spouses of marriage before the injury were less happy and felt less hopeful about the future than those who were married after the injury. They also found that the level of assistance provided in activities of daily living and hours per day spent assisting the persons with SCI were strongly correlated with depression in care-givers. The extent to which the care-giver felt burdened by the persons with SCI was inversely correlated with life satisfaction. Kester et $a l^{22}$ found that wives of persons with SCI reported a greater number of health problems than the normal controls. Most of these health problems had been persisting for more than 6 years. These findings thus point to the understanding that while the quality of life of persons with SCI may be improved through intensive care by their spouses, the quality of life of spouses may correspondingly deteriorate and be jeopardized. The well-being of spouses of SCI persons may need to be carefully considered and safeguarded given their relative high risk for developing into more severe psychological and psychiatric morbidities.

Although the psychosocial difficulties of the persons with SCI and their spouses had been examined in some detail, ${ }^{24,27}$ there are few available systematic researches on their family dynamics and marital relationships. Among the few studies on family and marital relationships reported, the marital stability of the persons with SCI was the major focus. ${ }^{14,33,34}$ However, continuation of marital relationship is at best a vague and unreliable indicator of marital adjustment. Quality of the marital relationship is the ultimate indicator of the health of any marriage. The life satisfaction and marital adjustment of persons with SCI and their spouses have not been fully explored, particularly in the context of the Chinese culture. ${ }^{35}$ The present study aims to explore the psychosocial response and adjustment in Hong Kong Chinese couples following SCI, and to examine the impact of care-giving experienced by spouses of persons with SCI. The potential differential patterns of adjustment in pre- and post-injury marriages were also explored to shed light and directions on rehabilitation interventions for patients with SCI and their spouses.

\section{Methods}

\section{Participants}

In Hong Kong, there is no central registration of patients by diagnosis similar to the mortality and morbidity statistics available in the United States and United Kingdom. It is thus difficult to estimate the exact number of persons suffering from SCI in Hong Kong. However, it has been estimated that there are a few hundred persons with SCI in Hong Kong and about $30 \%$ of SCI persons are married before or after the injury. ${ }^{21}$ The potential number of participants available for study would be around 100 . Participants were recruited from three main regional rehabilitation settings in Hong Kong Island, Kowloon Peninsula and the New Territories. These settings represent the major out-patient clinics for persons with SCI. Moreover, a community resources organization was also included in the sample pool so that persons who are not receiving active out-patient services may also be included. This community resources organization was the only official organization providing community consultation services for persons with various kinds of disability during the period of the present study. The sample pool thus included active out-patient cases as well as community SCI persons who are not actively involved in the medical service network. A total of 94 potential participants were identified. Sixty-six persons with SCI and 40 spouses agreed to take part in the present study. The average response rate for the study was $65.4 \%$. 
All persons with SCI who fulfil the criterion of at least 2 years' history of SCI are invited to participate in the study. Other inclusion criteria are: (1) diagnosed as either complete or incomplete paraplegia/quadriplegia; (2) has permanent impairment of strength, sensation, bowel or bladder, or sexual functioning; (3) once married (before or after injury, or divorced); (4) no problems in hearing, verbal communication and vision. The first two criteria were included to insure that the participants recruited were representative of the typical SCI persons commonly encountered in the rehabilitation milieu. Since personal and marital adjustment issues are more common during the later stage of a permanent residual disability, the criterion for 2years duration of injury was used to include participants who have gone through the acute treatment and physical restoration stages. ${ }^{2,36} \mathrm{Di}$ vorced participants were also recruited because the information gathered from them may provide valuable understanding into the reasons for separation or divorce. It is particularly important to identify factors leading to failure or maintenance of ongoing marital relationships. ${ }^{37}$ The fourth criterion was included to ensure that participants could understand all the procedures and participate meaningfully in the study. Participants should be able to reliably complete the instruments used to gather the information.

\section{Measures}

(1) Levenson's Internality, Powerful Others, and Chance Scale (LIPC) ${ }^{38}$ was used to measure the locus of controls. The scale consists of three subscales, internality, powerful others, and chance sub-scales. Each sub-scale comprises of eight items with a 6-point Likert format, ranging from -3 (strongly disagree) to +3 (strongly agree) with a constant of 24 added to the total to eliminate negative scores. Separate sub-scale scores are obtained, with higher scores indicating higher expectations of control by the source designated.

(2) Provision of Social Relationship (PSR) ${ }^{39}$ measured the participant's perception of social support. The measure consists of 15 items and is comprised of two sub-scales, ie family support and friend support. Two separate scores can be obtained with higher scores reflecting more social support perceived.

(3) Ways of Coping Checklist (WOC) ${ }^{40}$ was used to measure the coping styles of the participants. The checklist describes a broad range of coping and behavioural strategies tackling emotion- and problem-focused aspects and had been applied to persons with SCI. ${ }^{77}$ The checklist used in this study is a modified version (Folkman et $a l)^{40}$ consisting of 50 items. The checklist consists of eight sub-scales: confrontive coping, distancing, self-control, seeking social support, accepting responsibility, escape-avoiding, planful problem solving, and positive reappraisal. Scoring is based on yes - no response.

(4) Beck Depression Inventory (BDI $)^{41}$ is a scale widely used in assessing depression and often used with SCI. ${ }^{16,18}$ It consists of 21 statements exploring affective and somatic aspects of depression. Reliability and validity of this Chinese translated version has been reported with impressive findings. ${ }^{41,42}$

(5) Satisfaction with Life Situation (SWLS) ${ }^{43}$ measured the participant's life satisfaction. It consists of five items, each item is scored from 1-7 in terms of 'strongly disagree' to 'strongly agree'. A total score is obtained by adding all the items with higher scores reflecting more life satisfaction.

(6) Katz Adjustment Scale-Relative Form (KASR) ${ }^{44}$ measured the social adjustment in persons with SCI. ${ }^{24}$ The short version of the relative form 1 was used to measure behavioural symptoms and social behaviour. It consists of 85 items and gives a total score of its own. The higher the score the more maladjusted the participants. Relative form 2 and 3 measured performance of socially expected activities and relative's expectation of social role functioning respectively. A social role dissatisfaction score was obtained by subtracting form 2 by form 3 .

(7) Caregiver Burden Inventory (CBI ${ }^{45}$ measured the caregiving burden imposed on the spouses. It was specifically designed to measure the care-giving burden experienced by care-givers of neurologically impaired patients. ${ }^{45}$ It consists of 24 items tapping for time-dependence, developmental burden, physical burden, social burden, and emotional burden. The higher the scores of each sub-scale, the more severe the burden imposed on the spouses.

(8) Dyadic Adjustment Scale (DAS) ${ }^{46}$ measured the marital quality and adjustment pattern of the participants. It consists of 32 items tapping four aspects of marital quality: dyadic satisfaction, dyadic cohesion, dyadic consensus, and affection expression. Total scores can be obtained by adding all the items together with higher score indicating higher overall marital quality and adjustment. Separate scores on the four sub-scales can also be used to reflect different aspects of marital adjustment.

(9) Functional Independence Measure (FIM) ${ }^{47}$ measured the functional ability of persons with SCI. It is a well-known behavioural rating scale consisting of 18 items for both motor and social cognition. A seven-point scale is used to indicate different degrees of independent behaviour. The higher the score the more functionally independent will be the participant. 
All measures adopted for use have well documented psychometric properties in terms of reliability and validity. The FIM was rated only for persons with SCI, whereas the CBI was only administered to their spouses. Otherwise, all the participants received the same set of measures.

\section{Procedures}

Invitation letters were sent to designated rehabilitation settings and community resources organization. Potential participants were screened by the investigator on a set of inclusion criteria. Written consent was obtained from all the participants before the interviews and questionnaires were administered. An introductory interview was conducted by the investigator at the beginning of each session. Persons with SCI and their spouses were interviewed separately. The self-report questionnaires were read aloud by the investigator and the participants were asked to indicate their responses.

\section{Data analysis}

All data collected were analyzed with the Statistical Analysis System (SAS) for window, version 6.08. Descriptive statistics were used to summarize the data. Pearson correlation coefficients were calculated to determine the association between all the interval or ordinal variables. Two-tailed independent $t$-tests or Chi-square tests (with continuity correction) were performed on the demographic variables between group comparisons. Forward stepwise regression was used to determine the personal and marital adjustment outcomes in persons with SCI and their corresponding spouses. The criterion for adding variables was to select the variable with the least increase in the sum of squared errors. Adjusted R-square was used to determine the goodness of fit since it would selfadjust the number of variables and objects studied together with the consideration of the small sample size. $^{48}$

\section{Results}

Demographic characteristics of the participants

The mean age and duration of injury of the participants was $45.2(\mathrm{SD}=10.66)$ and 13.3 years $(\mathrm{SD}=10.01)$ respectively. The ratio of male to female was $4: 1$. The sample consisted of 22 complete paraplegia $(33.33 \%), \quad 16$ incomplete paraplegia (24.24\%), 15 complete quadriplegia $(22.73 \%)$, and 13 incomplete quadriplegia $(19.70 \%)$. Twenty-nine per cent of the SCI $(n=19)$ were caused by industrial accident, $29 \% \quad(n=19)$ by medical diseases, $21 \%$ $(n=14)$ were due to surgical complication, $17 \%$ $(n=11)$ were caused by traffic accident, and $7 \%$ $(n=3)$ were due to sports injury. Twenty-three per cent $(n=15)$ were employed and $77 \%(n=51)$ were unemployed. The mean age at diagnosis was 31.7 years $(\mathrm{SD}=11.27)$ and the mean time since injury was 13.3 years $(S D=10.01)$. Fifty-five per cent of the participants were married before the injury and $25 \%$ were married after the injury. Twenty per cent were divorced.

For the spouses, the mean age was 41.2 $(\mathrm{SD}=10.69)$. Sixty-three per cent $(n=25)$ were married before the injury. Thirty-five per cent of the spouses $(n=14)$ also suffered from some degree of physical impairment, eg poliomyelitis. Sixty-three per cent were unemployed and engaged in a full-time caring role for their injured partners. Persons with SCI and their interviewed spouses $(n=40)$ were similar to those without spouses interviewed $(n=26)$ on all aspects of demographic data except marital status (Chi-square $=26.61, \quad P=0.0001$ ). Sample without spouses interviewed composed of a higher percentage of post-injury marriage, and divorced participants.

Table 1 Personal and marital adjustment profiles of persons with SCI

\begin{tabular}{llccc}
\hline & & $\begin{array}{c}\text { Pre-injury Marriage } \\
(n=36)\end{array}$ & $\begin{array}{c}\text { Post-injury Marriage } \\
(n=17)\end{array}$ & $\begin{array}{c}\text { Divorced } \\
(n=13)\end{array}$ \\
\hline BDI & Mean (SD) & $18.67^{*}(9.09)$ & $10.71^{*}(7.90)$ & $15.60(11.22)$ \\
SWLS & Mean (SD) & $15.69(7.08)$ & $18.88(4.85)$ & $15.00(8.93)$ \\
KASR-1 & Mean (SD) & $130.53(16.64)$ & $150.00(70.46)$ & $139.10(27.74)$ \\
SRD & Mean (SD) & $6.06^{*}(4.45)$ & $1.47^{*}(3.81)$ & $5.78(3.53)$ \\
DAS & & & & \\
$\quad$ Total DAS & Mean (SD) & $103.08(17.54)$ & $113.47(15.08)$ & $68.10 \#(20.90)$ \\
$\quad$ Dyadic Consensus & Mean (SD) & $50.36(7.23)$ & $51.65(6.92)$ & $31.60 \#(13.62)$ \\
$\quad$ Dyadic Cohesion & Mean (SD) & $10.08(5.82)$ & $14.88(5.48)$ & $7.60 \#(9.07)$ \\
$\quad$ Dyadic Satisfaction & Mean (SD) & $34.89(5.53)$ & $37.76(5.45)$ & $24.20(8.70)$ \\
$\quad$ Affection Expression & Mean (SD) & $7.47 \quad(2.86)$ & $9.18(2.16)$ & $4.70 \#(2.41)$ \\
\hline
\end{tabular}

BDI = Beck Depression Inventory; SWLS = Satisfaction with Life Situation; KASR = Katz Adjustment Scale Relative Form; $\mathrm{SRD}=$ Social Role Dissatisfaction; DAS $=$ Dyadic Adjustment Scale; ${ }^{*} P<0.05$. $\# P<0.05$ for divorced group and other subgroups 
Personal and marital adjustment outcomes for persons with SCI and spouses

The mean scores of BDI for persons with SCI was $15.79(\mathrm{SD}=9.61)$. Participants in the pre-injury marriage sub-group were significantly more depressed (mean $=18.67, \mathrm{SD}=9.09)$ than those in the post-injury marriage sub-group $($ mean $=10.71, \mathrm{SD}=7.90)$ (Table 1). The mean score of SWLS for persons with SCI was $16.72(\mathrm{SD}=6.98)$. There was no significant difference in life satisfaction in participants with different marital statuses of $[\mathrm{F}(2,62)=1.89$, $P=0.1411$ ] (Table 1). The change in personality and social behaviour was not significantly different across the groups with different marital status $[\mathrm{F}(2,62)=1.02$, $P=0.3887]$. However, participants in the pre-injury marriage sub-group had more social role dissatisfaction as compared with those in the post-injury marriage sub-group $(P<0.05)$. The total mean score of DAS for persons with SCI was $100.97(\mathrm{SD}=22.48)$. Participants in the divorced sub-group had a significantly lower mean score in all the sub-scales of DAS, except dyadic satisfaction, than the other subgroups $[\mathrm{F}(2,62)=15.95, P=0.0001]$.

The mean score of BDI for spouses was 11.58 $(\mathrm{SD}=8.26) \quad($ Table 2). There was no significant difference in BDI score between spouses with preand post-injury marriages. The mean score of SWLS for spouses was $19.53(\mathrm{SD}=6.25)$. There was no significance difference in depression score between spouses with pre- and post-injury marriages. However, a significantly higher score in time-dependent burden was reported by spouses in the pre-injury marriage $(t=3.0143, \quad P=0.0046)$. Time-dependent burden was associated with the level of injury (Chisquare $=14.545, P=0.0001$ ). Scores on all other subscales of CBI were independent of the extent and level of injury. The mean score of the total DAS for spouses was $106.63(\mathrm{SD}=19.54)$. No significant difference was found between spouses in pre- and post-injury marriage.

Prediction of care-giving burden experienced by spouses The sub-scales of the CBI were used as the dependent variables for care-giving burden experienced by spouses. Five separate stepwise multiple regression analyses were performed. Chance control, problem-focused coping, total FIM score, and income were used as predictors of the developmental burden. Together the above variables accounted for $35 \%$ of variance $[\mathrm{F}(4,35)=6.273, \quad P=0.0006] \quad$ (Table 3). Orientation to chance control (Beta $=0.4590, t=3.139$, $P=0.0034)$ and endorsement of problem-focused coping (Beta $=0.4035, t=2.792, P=0.0083$ ) are associated with higher score in developmental burden. A lower burden was associated with better functional independence of the injured partners $($ Beta $=-0.2743$, $t=-2.086, P=0.0443$ ).

For the emotional burden, the variables of chance control $($ Beta $=0.3302, \quad t=2.146, \quad P=0.0209)$, time since injury $(\operatorname{Beta}=0.3067, t=2.254, P=0.0304)$, and social support $\quad($ Beta $=-0.3035, \quad t=-2.216$, $P=0.0018)$ were retained in the final regression model $[\mathrm{F}(3,36)=6.097, P=0.0018]$. Together the variables accounted for a total of $28 \%$ of variance. Orientation of chance control and longer time since injury are associated with higher emotional burden. Perceived social support is associated with lower emotional burden experienced by spouses.

Functional independence, income, emotion-focused coping, chance control, and age accounted for a total of $52 \%$ of variance of the physical caring burden $[\mathrm{F}(6,33)=7.779, P=0.0001]$. Functional independence and better household income are associated with lower

Table 2 Personal and marital adjustment profile of spouses

\begin{tabular}{llrr}
\hline & & $\begin{array}{c}\text { Pre-injury Marriage } \\
(n=25)\end{array}$ & $\begin{array}{c}\text { Post-injury } \\
(n=15)\end{array}$ \\
\hline BDI & Mean (SD) & $11.76(7.91)$ & $11.27(9.08)$ \\
SWLS & Mean (SD) & $19.72(6.45)$ & $19.20(6.11)$ \\
CBI & & \\
$\quad$ Developmental & Mean (SD) & $10.04(5.01)$ & $7.33(4.95)$ \\
$\quad$ Emotional & Mean (SD) & $3.33(4.56)$ \\
$\quad$ Physical & Mean (SD) & $6.48(4.05)$ & $6.92(5.36)$ \\
$\quad$ Social & Mean (SD) & $8.80(5.17)$ & $4.47(5.19)$ \\
DAS Time-dependent & Mean (SD) & $6.04(3.82)$ & $7.67(5.15)$ \\
Total DAS & & $12.52(4.80)$ & \\
$\quad$ Dyadic Consensus & Mean (SD) & $110.53(16.00)$ \\
$\quad$ Dyadic Cohesion & Mean (SD) & $104.28(15.26)$ & $48.67(8.54)$ \\
$\quad$ Dyadic Satisfaction & Mean (SD) & $15.13(6.14)$ \\
$\quad$ Affection Expression & Mean (SD) & $12.54(6.46)$ & $37.87(6.14)$ \\
\hline
\end{tabular}

$\mathrm{BDI}=$ Beck Depression Inventory; SWLS $=$ Satisfaction with Life Situation; $\mathrm{CBI}=$ Caregiving Burden Inventory; DAS $=\mathrm{Dy}$ adic Adjustment Scale; $* * * P<0.005$ 
Table 3 Regression model on marital adjustment and care-giving burden

\begin{tabular}{|c|c|c|c|c|c|}
\hline Variable & $\begin{array}{c}\text { Standardized } \\
\text { coefficient }\end{array}$ & $\mathrm{t}$-value & $\mathrm{P}$-value & $\begin{array}{c}\text { Adjusted } \\
R^{* *} R\end{array}$ & F-value \\
\hline \multicolumn{5}{|l|}{ SCI (Marital Adjustment) } & $(3,61)$ \\
\hline Gender & 0.4319 & 4.145 & 0.0001 & 0.3186 & $10.974 * * *$ \\
\hline Social support & 0.3038 & 2.866 & 0.0057 & & \\
\hline Income & 0.1867 & 1.766 & 0.0824 & & \\
\hline \multicolumn{5}{|l|}{ SPOUSE (Marital Adjustment) } & $(2,36)$ \\
\hline Social support & 0.4424 & 3.065 & 0.0041 & 0.2091 & $6.023^{*}$ \\
\hline Gender & -0.2208 & -1.530 & 0.1324 & & \\
\hline \multicolumn{5}{|l|}{ SPOUSE (Care-Giving Burden) } & $(2,36)$ \\
\hline \multicolumn{6}{|l|}{ Developmental Burden } \\
\hline Chance control & 0.4590 & 3.319 & 0.0034 & 0.3510 & $6.273 * *$ \\
\hline Problem-focused coping & 0.4035 & 2.797 & 0.0083 & & \\
\hline Functional independence & -0.2743 & -2.086 & 0.0443 & & \\
\hline Income & -0.2163 & -1.940 & 0.0605 & & \\
\hline \multicolumn{6}{|l|}{ Emotional Burden } \\
\hline Chance control & 0.3302 & 2.146 & 0.0209 & 0.2817 & $6.097^{*}$ \\
\hline Time since injury & 0.3067 & 2.254 & 0.0304 & & \\
\hline Social support & -0.3035 & -2.216 & 0.0331 & & \\
\hline \multicolumn{6}{|l|}{ Physical Burden } \\
\hline Functional independence & -0.4814 & -4.119 & 0.0002 & 0.5105 & $7.779 * * *$ \\
\hline Income & -0.4009 & -3.196 & 0.0031 & & \\
\hline Emotion-focused coping & 0.6039 & 4.072 & 0.0003 & & \\
\hline Chance control & 0.2480 & 2.080 & 0.0453 & & \\
\hline Age & 0.5620 & 2.467 & 0.0190 & & \\
\hline \multicolumn{6}{|l|}{ Social Burden } \\
\hline Social support & -0.3221 & -2.343 & 0.0249 & 0.2798 & $4.478 *$ \\
\hline Income & -0.3938 & -2.605 & 0.0134 & & \\
\hline Emotion-focused coping & 0.3539 & 2.350 & 0.0246 & & \\
\hline \multicolumn{6}{|l|}{ Time-dependent Burden } \\
\hline Functional independence & -0.7804 & -8.022 & 0.0001 & 0.6765 & $17.311 * * *$ \\
\hline Income & -0.4294 & -4.185 & 0.0002 & & \\
\hline Emotion-focused coping & 0.3034 & 2.971 & 0.0054 & & \\
\hline Gender & 0.2496 & 2.529 & 0.0163 & & \\
\hline Social support & 0.2571 & 2.459 & 0.0192 & & \\
\hline
\end{tabular}

Degrees of freedom in parentheses; $* P=0.005 ; * * P=0.001 ; * * * P=0.0001$

physical caring burden experienced by spouses. Functional independence alone accounts for $18 \%$ of variance. Endorsement of emotion-focused coping $($ Beta $=0.6039, \quad t=4.072, \quad P=0.003)$, orientation to chance control $($ Beta $=0.0678, t=2.08, \quad P=0.0453)$, and older age $($ Beta $=0.562, t=2.467, P=0.019)$ are associated with higher physical burden experienced by spouses.

Social support, income, and emotion-focused coping accounted for a total of $28 \%$ of variance of the social burden on spouses $[\mathrm{F}(4,53)=4.787, P=0.0035]$. Social support alone accounted for $12 \%$ of the variance. Higher perceived social support by spouses is associated with lower social caring burden $($ Beta $=-0.3221, t=-2.343, P=0.0249)$. Higher income is associated with lower social caring burden $($ Beta $=-0.918, t=-2.605, P=0.0134)$. Endorsement of emotion-focused coping (Beta $=-0.3539, t=2.350$, $P=0.0246)$ is associated with higher social caring burden.
Functional independence, income, emotion-focused coping, gender, and social support accounted for $68 \%$ of the various types of time-dependent caring burden $[\mathrm{F}(5,34)=17.311, \quad P=0.0001]$. Functional independence contributed $46 \%$ of the variance (Beta $=-0.7804, t=-8.002, P=0.0001)$. Better functional independence in persons with SCI is associated with lower time-dependent burden experienced by their spouses. Higher household income is associated with a lower time-dependent burden (Beta $=-0.0725$, $t=-4.185, \quad P=0.0002)$. Endorsement of emotionfocused coping $($ Beta $=0.0304, t=2.971, P=0.0054)$, being male (Beta $=0.2496, t=2.529, P=0.0163)$, and social support $($ Beta $=0.2571, t=2.459, P=0.0192)$ are associated with higher time-dependent caring burden.

\section{Discussion}

The mean depression score on the BDI for persons with SCI and their spouses were relatively high in 
reference to the suggested cut-off values (11 and 14). ${ }^{49}$ Disability seems to be particularly denounced in eastern culture. $\mathrm{Lee}^{50}$ suggested that intolerance of high population density and high levels of material aspiration may contribute to the emotional distress among Hong Kong Chinese. Against such a background, disability signifies 'uselessness', 'non-productivity', and 'dependency' to Chinese people. Disability can thus be regarded as a 'letdown' both in the eyes of the beholder as well as the disabled person him/herself. The letdown relates to an inability to live up to the traditional Chinese ideals of being 'able', 'productive', and 'independent', in being able to care for oneself as well as one's family members. ${ }^{51,52}$ The adverse effects of educational and economic disadvantages may also be an additional source of emotional distress in the disabled group. This is partially borne out in the available data indicating a significant inverse correlation between depression and income in persons with SCI.

The high depressive scores in spouses seem understandable as one of the adverse effects of living with a chronically disabled partner for a long time. Kester et $a l^{22}$ noted that compared to a healthy control group, spousal adjustment to living with a male with SCI was poorer measured in terms of general health and mental health problems. Since the majority of spouses in this study were female, a relatively high depression score may also be due to the gender-role differences. The higher rate of current and lifetime depressive disorder and incidence of reports of depressive symptoms in women compared to men has been well-documented among both in Chinese ${ }^{53}$ and western populations. ${ }^{54,55}$

It is interesting to note that life satisfaction reported by the persons with SCI and their spouses were relatively high despite their depressive scores. Information volunteered during the interview indicated that persons with SCI generally accepted a lower standard of life style. Most of the participants have changed their comparison level, ie in using their present situation - being disabled, as a reference point for evaluating their current life situation. With better acceptance and a more realistic expectation, our participants have thus reported a relatively healthy level of life satisfaction. The present finding is consistent with those reported in many western studies indicating that the majority of persons with SCI reported their current quality of life as good or excellent. $^{32,56}$

We noted a clear negative change in the personality and social behaviour of persons following their injury. Persons with SCI became more withdrawn, more helpless, and had more psychopathological like symptoms compared to previously. However, the spouses of SCI persons reported a more satisfactory rating on their injured partner's role performance. Since these scores were derived from the perceived difference between role performance before and after the injury, the discrepancy between spousal and self- rating may indicate that spouses tend to decrease their expectations of their injured partners' role performance to a larger extent than their injured partners. At interview, persons with SCI were obviously still concerned about their social role performance as breadwinner, husband, and father. Much of the expressed dissatisfactions and concerns were related to non-fulfilment of perceived roles, disadvantages associated with disability, and social discrimination. Divorced and widowed participants had a significantly higher social role dissatisfaction than those with intact marriages highlighting the importance of social role dissatisfaction as a vulnerability factor in the SCI population.

The social impact of the SCI on the spouses was reflected in the magnitude of their perceived caregiving burden. The relatively lower mean scores of care-giving burden reported by spouses may be due to the fact that they are generally not the sole person responsible for the care of the persons with SCI. Those with better socio-economic backgrounds often employed a maid to care for the persons with SCI and thus did not show any caring burden imposed on them. Such explanation seems to be partly supported by the finding of a significant inverse correlation between income and developmental, physical, social, and time-dependent burden. In addition, Chinese families are still commonly of an extended type. Help from other family members is often available to relieve part of the burden in caring. Despite the relatively low mean scores of care-giving burden reported by spouses, SCI seemed to exert a much greater impact on participants with a pre-injury marriage than those with a post-injury marriage. A significantly higher time-dependent caring burden was reported by spouses who were married prior to the injury. As persons with SCI often lose the ability to perform activities of daily living to varying degrees, spouses in the pre-injury marriage might find it difficult to devote more time and energy to helping their injured partners with many daily tasks. Items like 'My care receiver is dependent on me very much', or 'I do not have a minute's break from my care-giving chores' may reflect their stressful situations.

Although no significant difference in marital adjustment was found between participants with different marital states, those in the pre-injury marriage reported lower levels of dyadic consensus, cohesion, satisfaction, and affect expression than those in the post-injury marriage. Divorced participants reported the lowest level of marital adjustment. Such findings are consistent with those of Crewe and Krause's $^{32}$ that persons with SCI in pre-injury marriage were less satisfied with their marital relationships than those in the post-injury marriage. The majority of the divorced participants in the present study also reported that the injury was one of the main reasons contributing to their divorce. It is interesting, however, to point out that in comparing 
SCI persons with maladjusted and well-adjusted groups of normal participants studied locally, ${ }^{57}$ the SCI group tends to fare in between the well-adjusted and the maladjusted group in terms of dyadic cohesion, dyadic satisfaction, and affection expression.

Functional independence of persons with SCI was not noted to be significantly correlated with the various adjustment outcomes of persons with SCI. Functional independence by the very nature should include physical, cognitive and social components. Persons with SCI in this study mainly suffered from physical impairment without cognitive impairment. This may explain partly why the sole impact of physical impairment does not correlate much with adjustment outcomes of persons with SCI. On the other hand, role ambiguities experienced by persons with SCI and their spouses may also confuse the association of functional independence on various outcomes. Zahn ${ }^{58}$ suggests that a clear-cut functional limitation may require the individual with disability to be cast in a sick role accepting of sympathetic and humanitarian responses, and help from family members. Therefore, those with a functional independence mid-way along the continuum may receive more negative consequences than those falling onto the two poles. Such a trend is partially evidenced by the significant inverse correlation between functional independence and social role dissatisfaction reported by persons with SCI, and that between functional independence and social role dissatisfaction reported by spouses. The disabled role, according to Peterson, ${ }^{59}$ may alter the expectations of both the individuals and family members, and hence complicates the predictive power of functional independence on adjustment outcomes.

\section{Limitations}

The sample recruited in this study was a non-random one. The present study is based on a relatively small sample size and multiple statistical comparisons without correcting for the increased likelihood of making a Type I error. The power and generalizability of the findings in the study may thus be limited. A more stringent significance level was not adopted since it was thought that the consequence of making a Type II error was equally problematic. The present study serves an exploratory role into the personal and marital adjustment outcomes of persons with SCI among the Hong Kong Chinese. Further research recruiting a larger sample size is needed to confirm these findings.

Data were only gathered from divorced persons with SCI concerning the reasons for divorce, but no data were gathered from the divorced spouses. Since the perceptions of the persons with SCI on the issue of personal and marital adjustment may differ from those of their divorced spouses, our study was not able to address such differences. On the other hand, recent research also indicates that those persons with SCI married after the injury are different in some ways from persons who get married before the injury and may thus be predisposed to better marital outcomes. ${ }^{13,14,32}$ Therefore, a more comprehensive comparison of the demographic and socio-economic background of SCI persons with pre- and post-injury marriages should be conducted in future studies.

The study adopted a cross-sectional design. Any causal inferences are thus unwarranted. The current design is also unsuited for clarifying any developmental patterns and evolution of the adjustment process of persons with SCI and their spouses.

\section{Implications}

The impact of SCI is a long-lasting effect not limited to the individuals concerned but also extending to their spouses and other family members. Findings from the adjustment outcomes and coping styles of persons with SCI and their spouses indicate that they are not 'passive' victims. A similar injury often produced different outcomes in different individuals. Rehabilitation professionals should thus be alert to the patients' and their spouses' differing needs and idiosyncrasies in their helping process. There seems to be the need to manipulate cognitive beliefs and coping variables like locus of control, cognitive appraisal, and modes of coping in helping to achieve more optimal personal and marital adjustment. Future emphasis of work in this area should be focused on the evaluation of the effectiveness and efficacy of these programmes.

As most marital separations took place during the early stage of the injury, where a higher frequency of depressive symptoms are often reported, early detection and screening of high-risk group is recommended. Counselling which aimed towards alleviating the specific stress associated with the injury and the disability should be provided. By addressing the actual needs of both members of the couple, distorted perceptions may be more effectively dealt with and better communication may be achieved between the injured person and their spouse. It is also important to balance the disparity between the spouses' expectations and the actual performance of leisure activities. The frustration of unmet expectations may be decreased by building up more realistic expectations, as well as practical suggestions about participation in recreational activities, including the problem of overcoming practical and physical barriers.

\section{Acknowledgements}

The findings of this article formed parts of the first author's M Phil dissertation under the supervision of the second and third authors. The first author is now a doctoral student at the Department of Psychology, The University of Hong Kong. 


\section{References}

1 DeVivo MJ, Fine PR, Maetz HM, Stover SL. Prevalence of spinal cord injury: a re-estimation of employing life table techniques. Arch Neurol 1980; 37: 707-708.

2 Kerr WG, Thompson MA. Acceptance of disability of sudden onset in paraplegia. Paraplegia 1972; 10: $94-1102$.

3 Hohmann GW. Psychological aspects of treatment and rehabilitation of the spinal cord injured person. Clin Ortho Res 1975; 112: $81-88$.

4 Bourestom NC, Howard MT. Personality characteristics of three disability groups. Arch Phys Med Rehab 1965; 46: 626-632.

5 Shontz FC. Physical disability and personality. In Neff, W.S. (ed) Rehabilitation Psychology. American Psychologists Association, Inc. 1971.

6 Safilos-Rothschild, C. The sociology and social psychology of disability and rehabilitation. Random House, New York 1970.

7 Dunn M. Social discomfort in the patients with spinal cord injury. Arch Phys Med Rehab 1977; 58: 257-260.

8 Trieschmann RB. Spinal cord injuries: psychological, social and vocational adjustment. Pergamon General Psychology Series. Pergamon Press 1980.

9 Frank RG, Elliott TR. Spinal cord injury and health locus of control briefs. Paraplegia 1989; 27: 250-256.

10 Steinbauer JR. Spinal injury: impact and implications for family medicine research. In Ramsey, C.N. (ed) Family systems in medicine. The Guildford Press: New York 1989.

11 Creek $\mathrm{G}$ et al. Personal and social implications of spinal cord injury: a retrospective study. Thames Polytechnic, Britain 1989.

12 DeVivo MJ, Fine PR. Spinal cord injury: its short-term impact on marital status. Arch Phys Med Rehab 1985; 66: $501-504$.

13 Brown JS, Giesy B. Marital status of persons with spinal cord injury. Soc Sci Med 1986; 23: 313-322.

14 DeVivo MJ, Hawkins LN, Richards SJ, Go BK. Outcomes of post-spinal cord injury marriages. Arch Phys Med Rehab 1995; 76: $130-138$

15 Buckelew SP et al. Adjustment to spinal cord injury: stage theory re-visited. Paraplegia 1991; 29: 125-130.

16 Craig AR, Hancock KM, Dickson HG. Spinal cord injury: a search for determinants of depression two years after the event. Br J Clin Psychol 1994; 33: 221 - 230.

17 Frank RG et al. Differences in coping styles among persons with spinal cord injury: a cluster-analytic approach. J Consult Clin Psychol 1987; 55: $727-731$.

18 Hancock K, Craig A, Tennant C, Chang E. The influence of spinal cord injury on coping styles and self-perceptions: a controlled study. Aus New Zealand J Psych 1993; 27: 450-456.

19 Anson CA, Stanwyck DJ, Krause JS. Social support and health status in spinal cord injury. Paraplegia 1993; 31: 632-638.

20 Fung WYP. Stress and coping strategies of patients with ankylosing spondylitis. Unpublished Master Dissertation, The University of Hong Kong 1991.

21 Tseng CMY. A study of social support and adjustment to spinal cord injury. Unpublished master dissertation. The Chinese University of Hong Kong 1987.

22 Kester BL, Rothblum ED, Lobato D, Milhous RL. Spouse adjustment to spinal cord injury: long-term medical and psychosocial factors. Rehabilitation Counseling Bulletin 1988; 32: $4-21$.

23 McGowan MG, Roth S. Family functioning and functional independence in spinal cord injury adjustment. Paraplegia 1987; 25: $357-365$.

24 Stambrook $\mathrm{M}$ et al. Social role functioning following spinal cord injury. Paraplegia 1991; 29: 318 -323.

25 Burman B, Margolin G. Analysis of the association between marital relationships and health problems: an interactional perspective. Psychol Bull 1992; 112: 39-63.

26 Schulz RC, Decker S. Long-term adjustment to physical disability: the role of social support, perceived control, and self-blame. J Person Soc Psychol 1985; 48: 1162-1172.
27 Schulz RC, Tompkins CA, Wood D, Decker S. The social psychology of caregiving: physical and psychological costs of providing support to the disabled. J Appl Soc Psychol 1987; 17: $401-428$.

28 Urey JR, Henggeler SW. Marital adjustment following spinal cord injury. Arch Phys Med Rehabil 1987; 68: 69-74.

29 Kennedy P, Fisher K, Pearson E. Ecological evaluation of a rehabilitative environment for spinal cord injured people: behavioural mapping and feedback. Br J Clin Psychol 1988; 27: $239-246$

30 Crewe NM, Athelstan GT, Krumberger J. Spinal cord injury: a comparison of pre-injury and post-injury marriages. Arch Phys Med Rehab 1979; 60: 252 - 256.

31 Crewe NM, Krause JS. Marital relationships and spinal cord injury. Arch Phys Med Rehab 1988; 69: 435-438.

32 Crewe NM, Krause JS. An eleven-year follow-up of adjustment to spinal cord injury. Rehabil Psychol 1991; 35: $205-210$.

33 El Ghatit AZ, Hanson RW. Outcome of marriages existing at the time of a male's spinal cord injury. J Chron Dis 1975; 28: $383-$ 388.

34 El Ghatit AZ, Hanson RW. Marriage and divorce after spinal cord injury. Arch Phys Med Rehab 1976; 57: 470-472.

35 Yim SY et al. Quality of marital life in Korean spinal cord injured patients. Spinal Cord 1998; 36: 826-831.

36 Lundqvist $\mathrm{C}$ et al. Spinal cord injuries: clinical, functional and emotional status. Spine 1991; 16: $78-83$.

37 Peters LC et al. Differential effects of spinal cord injury and head injury on marital adjustment. Brain Injury 1992; 6: 461 - 467.

38 Levenson HI. Activism and powerful others: distinctions within the concept of internal-external control. J Person Assess 1974; 38: $377-385$.

39 Turner RJ, Frankel BG, Levin DM. Social support: conceptualization, measurement, and implications for mental health. Res Comm Mental Health 1983; 3: 67-111.

40 Folkman S et al. Dynamics of a stressful encounter: cognitive appraisal, coping, and encounter outcomes. J Person Soc Psychol 1986; 50: $992-1003$

41 Chan CM, Tsoi MM. The BDI and stimulus determinants of cognitive-related depression among Chinese college students. Cog Ther Res 1984; 8: $501-508$.

42 Shek DTL. Reliability and factorial structure of the Chinese version of the Beck Depression Inventory. J Clin Psych 1990; 46: $35-43$.

43 Diener E, Emmons RA, Larsen RJ, Griffin S. The satisfaction with life scale. Person Assess 1985; 49: 71-75.

44 Katz MM, Lyerly SB. Methods for measuring adjustment and social behaviour in the community: I. Rational, description, discriminative validity and scale development. Psychol Reports 1963; 13: $503-535$.

45 Novak M, Guest C. Application of a multidimensional caregiver burden inventory. Gerontologist 1989; 29: $798-803$.

46 Spanier GB. Measuring dyadic adjustment: new scales for assessing the quality of marriage and similar dyads. $J$ Marriage Family 1976; 38: 15-28.

47 Centre for Functional Assessment and Research, State University of New York. Functional Independence Measure Manual 1990.

48 Hair JF, Anderson RE, Tatham RL, Black WC. Multivariate Data Analysis with Readings. New York: Macmillan Publishing Company 1992.

49 Judd FK, Brown DJ, Burrows CD. Depression, disease and disability: application to patients with traumatic spinal cord injury. Paraplegia 1991; 29: $91-96$.

50 Lee RPL. Social stress and coping behaviour in Hong Kong. In: Tseng WS, Wu DYH (eds). Chinese Culture and Mental Health, Academic Press 1985, pp. 193-214.

51 Lin KM. Traditional Chinese medical beliefs and their relevance for mental illness and psychiatry. In: Kleinmann A, Lin TT (eds). Normal and abnormal behaviour in Chinese culture. Reidel Publishing Co. 1981. 
52 Koo LC. A journey into the cultural aspects of health and illhealth in Chinese society in Hong Kong: the importance of health and preventive medicine in Chinese society. J Comm Health 1989; 11: $51-58$.

53 Lin N, Dean A, Ensel W. Social support, life events, and depression. Orlando: Academic Press 1986.

54 Gove W, Tudor J. Adult sex roles and mental illness. Am J Sociol 1973; 77: $812-835$.

55 Weissman MM, Klerman GL. Sex differences and the epidemiology of depression. Arch Gen Psych 1977; 34: 98-111.
56 Whiteneck GG et al. Mortality, morbidity, and psychosocial outcomes of persons with spinal cord injury more than 20 years ago. Paraplegia 1992; 30: 617-630.

57 Shek DTL. Psychometric properties of the Dyadic Adjustment Scale. Psychologia 1994; 37: 7-17.

58 Zahn MA. Incapacity, impotence and invisible impairment: their effects upon interpersonal relations. J Health Social Behaviour 1973; 14: $115-123$

59 Peterson Y. The impact of disability on marital adjustment: a literature review. The Family Coordinator 1979; 47-51. 